\title{
An Agent-Based Model for Addressing the Impact of a Disaster on Access to Primary Care Services
}

\author{
Hasan Guclu, PhD; Supriya Kumar, PhD, MPH; David Galloway, MS; \\ Mary Krauland, PhD; Rishi Sood, MPH; Angelica Bocour, MPH; \\ Tina Batra Hershey, JD, MPH; Elizabeth van Nostrand, JD; Margaret Potter, JD, MS
}

\section{ABSTRACT}

Objective: Hurricane Sandy in the Rockaways, Queens, forced residents to evacuate and primary care providers to close or curtail operations. A large deficit in primary care access was apparent in the immediate aftermath of the storm. Our objective was to build a computational model to aid responders in planning to situate primary care services in a disaster-affected area.

Methods: Using an agent-based modeling platform, HAZEL, we simulated the Rockaways population, its evacuation behavior, and primary care providers' availability in the aftermath of Hurricane Sandy. Data sources for this model included post-storm and community health surveys from New York City, a survey of the Rockaways primary care providers, and research literature. The model then tested geospatially specific interventions to address storm-related access deficits.

Results: The model revealed that areas of high primary care access deficit were concentrated in the eastern part of the Rockaways. Placing mobile health clinics in the most populous census tracts reduced the access deficit significantly, whereas increasing providers' capacity by $50 \%$ reduced the deficit to a lesser degree.

Conclusions: An agent-based model may be a useful tool to have in place so that policy makers can conduct scenario-based analyses to plan interventions optimally in the event of a disaster. (Disaster Med Public Health Preparedness. 2016;10:386-393)

Key Words: primary care access, planning, agent-based model, spatial, hurricane, Superstorm Sandy

$\mathrm{H}$ urricane Sandy was the second largest and costliest hurricane in the United States after Katrina. ${ }^{1}$ It was responsible for more than 200 deaths across 8 countries and significantly damaged infrastructure and hampered access to health care services in the low-lying neighborhoods of different regions including New York City. In the United States, Hurricane Sandy disrupted the overall functioning of the health care system, ${ }^{2-4}$ including routine visits to primary care providers (PCPs) ${ }^{5,6}$ and access to hospitals and emergency rooms, ${ }^{7-10}$ dialysis, ${ }^{11,12}$ gynecology services, ${ }^{13}$ and mental health providers. Numerous factors related to operations of health facilities contributed to issues with access to primary health care. These factors included building and infrastructure damage, widespread power outages, and issues with transportation systems.

Measuring the impact of Hurricane Sandy on the primary health care system in heavily affected areas is important to effectively plan for future disasters. Spatiotemporal assessment of primary health care deficit, ie, the difference between demand and capacity, requires a framework where demand and capacity can be modeled separately on the basis of real data. Agent-based modeling is a proven framework to study spatiotemporal aspects of dynamic systems. ${ }^{14}$

The Rockaway Peninsula (referred to as "the Rockaways") is an ideal neighborhood for using agent-based modeling to study the impact of a significant coastal storm on primary care access, including physician practices, hospital and other ambulatory care facilities, and other facilities that we consider to be major contributors to meeting primary care needs (eg, pharmacies). The unique characteristics of the Rockaways include a relatively diverse area with a range of socioeconomic, housing, and health care coverage types; geographic isolation with limited public and private transportation options; a single hospital and one federally qualified health center with 2 sites; a relatively high proportion of Medicaid enrollees; severe impact from Hurricane Sandy; and the subject of considerable post-Sandy efforts by the New York City Department of Health and Mental Hygiene (DOHMH) and other organizations to determine the need for and availability of primary care services. 
Our main objective in this study was to examine primary care need in the Rockaways by using an agent-based model. This model simulated the population, PCPs, and dynamic interactions between these groups. Based on these dynamics, the model simulated a primary care access deficit as a function of time in different census tracts in the Rockaways. One potential approach to reduce a primary care access deficit is to increase the capacity of health facilities to serve more patients. Although the total number of open practices may change in time, at any point, increasing the number of health care providers at specific practices can influence capacity. Another approach to address temporary deficits in access to primary care, which has been utilized after previous disasters, is the deployment of mobile health clinics (MHCs). ${ }^{15} \mathrm{MHCs}$ were deployed after Hurricane Sandy by various hospital systems and health center organizations, and these organizations were coordinating with the state and city health departments. After Hurricane Sandy, MHCs provided more than 1000 displaced individuals with primary care services in various heavily impacted areas of New York City. ${ }^{16}$ One obstacle in deploying MHCs is assessing the need in the community for primary health care ${ }^{6}$ to direct these resources to locations where they can be most effectively accessed. Therefore, another objective of this study was to assess the effect of deploying MHCs in reducing health care deficits and to examine the impact of alternative MHC locations on reducing the access deficit in local areas over time.

Here we report on an agent-based model to simulate the complex dynamic system of population and primary health care providers on the Rockaway Peninsula in New York City. The model represents a spatially explicit counterfactual laboratory ${ }^{17}$ in which to assess the impact of alternative interventions. The use of the census tract subdivision within the model has the potential to assist decision-makers in emergency response planning and real-time, post-disaster response activities.

\section{METHODS}

To assess the primary care deficit in the Rockaways, we used the agent model HAZEL (HAZard-area rEsource Locator), which is named after the first female African American general in the US Army, Hazel Brown-Johnson (1927-2011). HAZEL is designed to be a tool for public health decisionmakers to use for monitoring and evaluating the ongoing progress of restoring access to primary care in disaster-affected areas as well as for long-term planning. HAZEL allows for each access variable to be modified or held constant in relation to others, so that their relative impact on the access deficit can be observed in the simulation environment. Thus, the decision-maker can (1) test interventions experimentally, comparing past experience with alternative decisions to aid in planning for future events; (2) test which components of need and capacity have the greatest impact on short-term and long-term access deficits-suggesting whether, when, and how to target interventions; and (3) test whether policy changes_-such as loosening Medicaid eligibility restrictions-might improve primary care recovery.

\section{The Agent-Based Modeling Framework}

HAZEL is designed as one module in a larger simulation system called Framework for Reconstructing Epidemic Dynamics (FRED), ${ }^{18}$ which is an open-source agent-based modeling and simulation platform funded by the National Institutes of Health to simulate the daily activities and interactions of millions of individuals. FRED was originally designed to study epidemic dynamics; however, it has additional functionality to be used for other purposes such as simulating post-disaster primary care access. For example, FRED has been used to evaluate potential responses to influenza pandemics, including vaccination policies, ${ }^{19}$ school closure, ${ }^{19,20}$ social distancing behavior, ${ }^{21}$ and the effects of commuting modalities, ${ }^{22}$ as well as to examine the causes of spatial inequalities in infectious disease. ${ }^{23}$ Key features of FRED include realistic synthetic populations based on the US Census Bureau's Public Use Microdata Files and Census aggregated data, specification of agent health status and social networks, specification of agent behavior and decision rules, and scalability. In freely available synthetic population data developed by RTI International as part of the MIDAS project, each agent has a set of sociodemographic characteristics that include age, sex, race, household income, and employment and school enrollment status. Each household is mapped to a specific geographic location. FRED is very scalable; namely, it can run on a variety of computer platforms from laptops to supercomputers, depending on the size of the population being simulated.

To model primary care access deficit, we parameterized the attributes of individuals and practices in HAZEL by using various data sources (see the supplementary tables in the online data supplement).

\section{The agent attributes were as follows:}

1. Demographics: In our synthetic population data we included several demographic attributes, such as age, sex, and exact household location.

2. PCP assignment: We assigned individual agents to their PCPs on the basis of the distance between them, PCP type, and their insurance type. We used a gravity model ${ }^{24}$ to assign agents to their PCPs. Namely, the agents were highly likely to be assigned to PCPs closer to where they lived as long as their capacity permitted it and the provider accepted the agent's insurance. We had 3 types of providers by specialty: pediatricians, family medicine physicians, and internal medicine physicians. We assumed that pediatricians saw only children under the age of 18 years, internal medicine physicians saw only adults, and family medicine physicians saw both children and adults. 
3. Insurance type: Agents were given a type of health insurance to match proportions of each health insurance type among respondents residing in Rockaways zip codes in the DOHMH Community Health Survey (CHS) from 2010 to 2012, ${ }^{25}$ including Medicare, Medicaid, private insurance, and no insurance. Owing to the small sample size of Rockaways, we had to aggregate 3 years in the survey. The $3 \%$ of respondents who had the "other" insurance type were proportionally rolled into the aforementioned 4 insurance types. We assumed that insurance type was correlated with household income so that only low-income households could have Medicaid. To simulate this we used a probability of being a Medicaid enrollee that is proportional to (1-hh_income/threshold), where hh_income is the household income, threshold is chosen as the twice the minimum household income in the area, and only those individuals with household income less than the threshold are assigned to Medicaid.

4. Chronic conditions among adults: Prevalence of asthma, hypertension, and diabetes among adult agents was based on self-reported prevalence estimates from the DOHMH 2012 CHS. $^{25}$

5. Chronic conditions among children: Prevalence of diabetes and asthma among children was based on data from Dabelea et $\mathrm{al}^{26}$ and the CDC National Health Interview Survey 2012 report, ${ }^{27}$ respectively.

6. Frequency of PCP visits: Agents accessed their assigned PCP on the basis of their age and chronic condition (if any). Age-specific average number of annual visits to a PCP was determined from Petterson et al. ${ }^{28}$ The average number of annual visits was divided by 250 to estimate the daily probability of accessing a PCP. Because private insurance was correlated with between 1.04 and 1.21 times more PCP visits, ${ }^{29}$ we assumed that agents with private insurance visited a PCP 1.1 times more than did agents with Medicaid. According to Ostbye et $\mathrm{al}^{30}$ we assumed that agents with chronic conditions utilized primary care at twice the rate as agents without chronic conditions, ie, their daily probability of accessing a PCP was twice that shown in the table in the online data supplement for their age and insurance type.

7. Evacuation estimates: We used the DOHMH 2013 CHS to give agents a probability of evacuation starting 3 days before the hurricane made landfall and a probability of return starting the day after the hurricane struck. Using responses to the following questions from residents of the Rockaways, we estimated the proportion of residents who were present in the Rockaways beginning 3 days before the hurricane and through the end of the simulation (100 days). (a) Did you evacuate from your home, at any time, because of Hurricane Sandy? (Yes/No) (b) Did you first evacuate your home before, during, or after Hurricane Sandy? (c) How many days were you not able to stay in your home because of the need to evacuate because of Hurricane Sandy? $(<7,7-30$, $31-90,>90$ days, still unable to return/home destroyed). We fit exponential functions to the survey data to estimate these probabilities (Figure 1).

The practice attributes were as follows. To create a complete system of interacting individuals and practices, we extended the definition of an agent to not only individuals but also practices with self-decision mechanisms. In 2014, the DOHMH conducted a survey among primary care practices in the Rockaways to determine Hurricane Sandy's impact on primary care. Forty of the universe of 46 practices in the Rockaways responded to the survey. We used the results of this survey (provider survey) to obtain agent attributes for the providers in that area. ${ }^{31}$ Survey results provided the exact

\section{FIGURE 1}

\section{(A) Evacuation and Return Behavior of the Rockaways Resident Population in the Days Before and After Hurricane Sandy. (B) Exponential Distributions Fit to the Data Provided Probability of Evacuation and Return Parameters for the Model.}

(A)

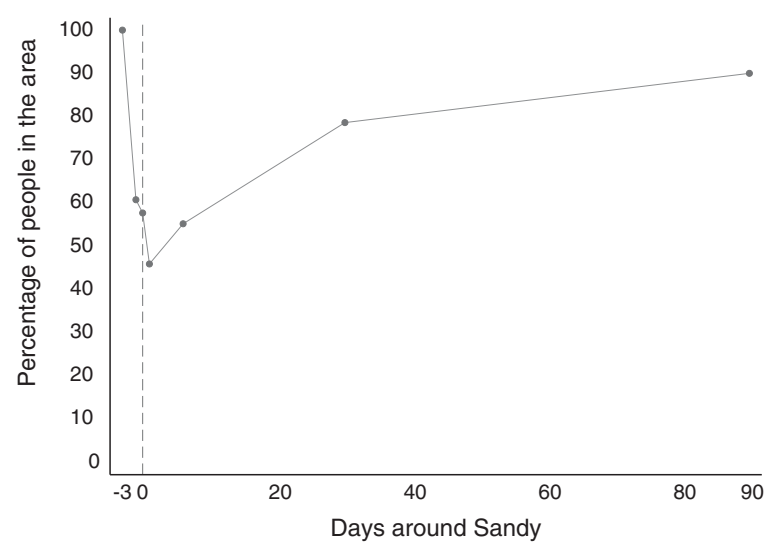

(B)

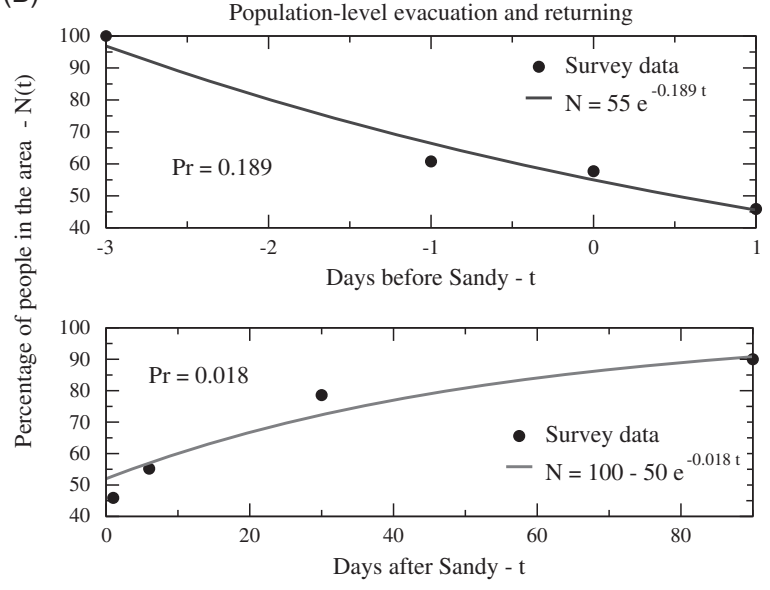


location, insurance types accepted, panel size, whether the practice closed in response to Sandy, whether the practice temporarily increased their panel size after Sandy, and when they reopened in their original location.

1. Panel size: We used the data on whether a provider reported increasing their panel size after Sandy to parameterize their ability to increase their capacity in the immediate aftermath of the storm: ie, providers who reported that they increased their panel size after Sandy were able to see $50 \%$ more patients immediately after Sandy in the excess capacity scenario described below.

2. Practice closure and reopening: We used the provider survey results in assigning durations of closures to practices.

Legal data were used to contextualize the agents operating in the HAZEL framework. Such legal data included provider scope of practice and licensure portability; the waiver of certain laws, regulations, and policies during declared emergencies and associated executive orders; and credentialing of volunteer providers and other issues related to volunteers. These data informed how agents could behave within the model.

\section{Simulation Scenarios}

Scenarios included a baseline scenario (a hurricane strikes the Rockaways on day 5 of the simulation and there is no intervention to reduce the access deficit), a scenario in which a subset of providers increased their capacity by $50 \%$ (ie, they were able to see $50 \%$ more patients per day), and a third scenario in which $6 \mathrm{MHCs}$ were active starting 3 days after the hurricane strikes (in the most populous census tracts or in the actual locations used by New York City in 2012 32 ) for 30 days. The interventions were designed to address possible changes in the law that might (1) enable increased provider capacity because of an expansion in practitioner scope of practice via waiver of law (eg, allowing physician assistants to perform certain services without physician supervision or through volunteer providers), and (2) allow MHCs to be included in vehicle categories exempt from any transportation limitations via executive order.

Each scenario was run 20 times and an average access deficit was calculated on each day along with a $95 \%$ confidence interval. Access deficit was defined as the number of people who sought and were unable to access care at a provider who accepted their insurance type. MHCs accepted all insurance types. The daily number of people unable to get care with a provider who accepted their insurance type was also mapped in each census tract.

\section{RESULTS}

\section{Parameters from CHS and Provider Surveys}

Evacuation and return dynamics for Rockaway residents are as shown in Figure 1A: 39\% evacuated before the storm, $3 \%$ during the storm, and $13 \%$ after the hurricane (we assumed all evacuees had finished evacuation 1 day after the storm). Twenty percent of those who evacuated returned within 7 days after the storm. The rate of return slowed thereafter, with $42 \%$ returning 7 to 30 days after, and another $20 \%$ returning 30 to 90 days after the storm and 15\% returning after 90 days. The daily probability of evacuation and return after fitting exponential distributions to these data are shown in Figure 1B.

\section{HAZEL Baseline Scenario}

With dynamically evacuating and returning agents and providers who closed and reopened in response to the storm, HAZEL could now be queried to examine the daily primary care access deficit, ie, the number of people who sought care and could not receive it. In the baseline scenario, Hurricane Sandy struck the Rockaways on day 5. Agents evacuated starting on day 2 of the simulation and returned starting on day 6 and continuing through day 100 . Primary care sites reopened 10, 21, and 60 days after the hurricane struck. This is visible as drops in the number of people unable to get care from a provider who accepted their insurance type on these days in Figure 2. By day 100 of the simulation, the deficit was at a level below that on day 0 because not all evacuated agents had returned by this time.

\section{Scenario With Provider Capacity Increase}

Providers who reported that their capacity increased after Hurricane Sandy were simulated to have a 50\% higher capacity in the immediate aftermath of Sandy in order to examine the impact of increasing provider capacity on access deficit. As shown in Figure 3 (green line), the ability of these providers to exceed their pre-Sandy capacity resulted in a modest decrease in the deficit compared to the baseline scenario.

\section{FIGURE 2}

Baseline Scenario Showing the Number of People Who Sought Health Care Each Simulated Day (Black) and the Number Unable to Get Care From a Primary Care Provider Who Accepted Their Insurance Type (Red).

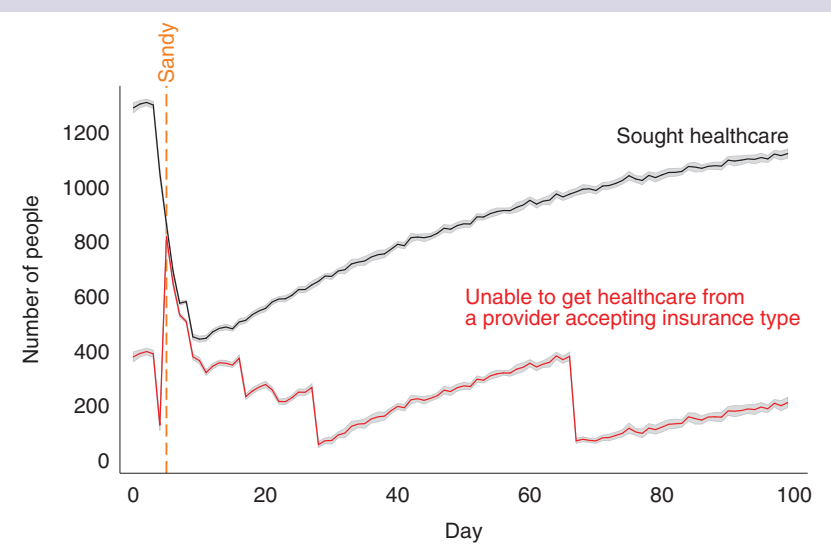

Note. The day when the hurricane struck is shown as a dashed line in orange. 


\section{Scenarios With Mobile Health Clinics}

When MHCs were placed in the 6 most populous tracts in the Rockaways starting day 5 after the hurricane, we observed a sharp drop in the number of people unable to access primary care (Figure 3, blue line). MHCs reduced the

\section{FIGURE 3}

\section{Primary Care Access Deficit Under the Baseline (Black) and 2 Alternate Scenarios: Selected Providers Increased Capacity by $\mathbf{5 0 \%}$ (Green) or MHCs Were Placed in the 6 Most Populous Census Tracts of the Rockaways (Blue).}

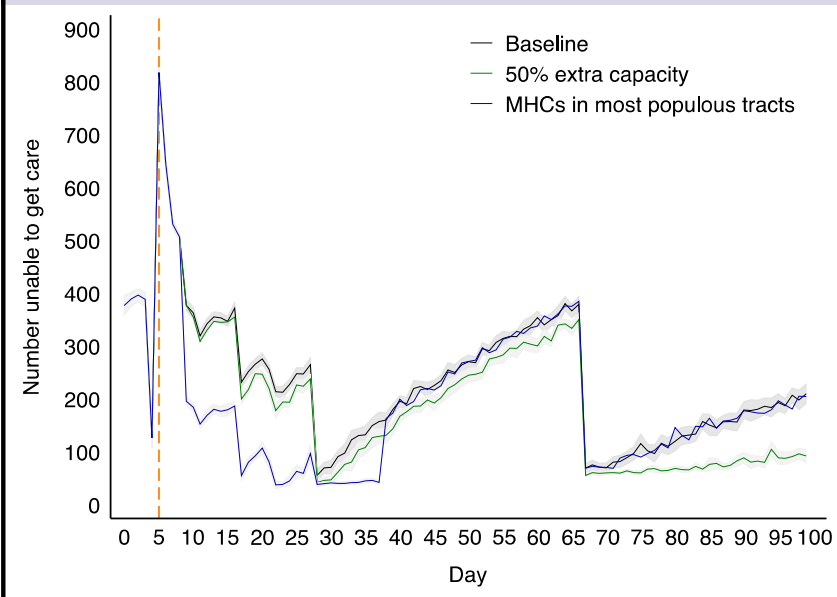

Note. $95 \%$ confidence intervals are shown as gray shaded areas. The day when the hurricane struck is shown as a dashed line in orange. Abbreviation: MHC, mobile health clinic. number of people unable to access care compared to the baseline scenario in the 30 days for which they functioned. Figure 4 shows maps of the Rockaways under the 3 scenarios. With MHCs in the most populous tracts, deficit was reduced to the lowest level in all tracts (Figure 4C).

In another formulation of this scenario, we simulated a primary care deficit when MHCs were placed in locations that were used in New York City during the Sandy response (see Figure S1 in the online data supplement). ${ }^{32}$ The deficit in this scenario was comparable to that in the scenario in which MHCs were placed in the most populous tracts (Figure S2 in the online data supplement).

\section{Sensitivity Analyses}

We examined sensitivity of the model to various agent and provider behavioral parameters. Holding evacuation probability and return probability of agents constant at the baseline levels, the model showed a nonlinear increase in deficit as the daily probability of seeking health care was varied from $50 \%$ lower to $50 \%$ higher than the baseline value. There was a sharp increase in deficit when agents sought care with a higher probability than at baseline (Figure 5A). Deficit decreased as evacuation probability increased, also showing hints of nonlinearity with steeper decreases at values below the baseline evacuation probability (0.189) than above (Figure 5B). Deficit in the model was somewhat less sensitive to the rate of return, although the deficit increased, as expected, with the daily return probability (Figure 5C).

\section{FIGURE 4}

Census Tracts Color-Coded to Depict the Number of People Unable to Get Care From a Provider Who Accepted Their Insurance Type.
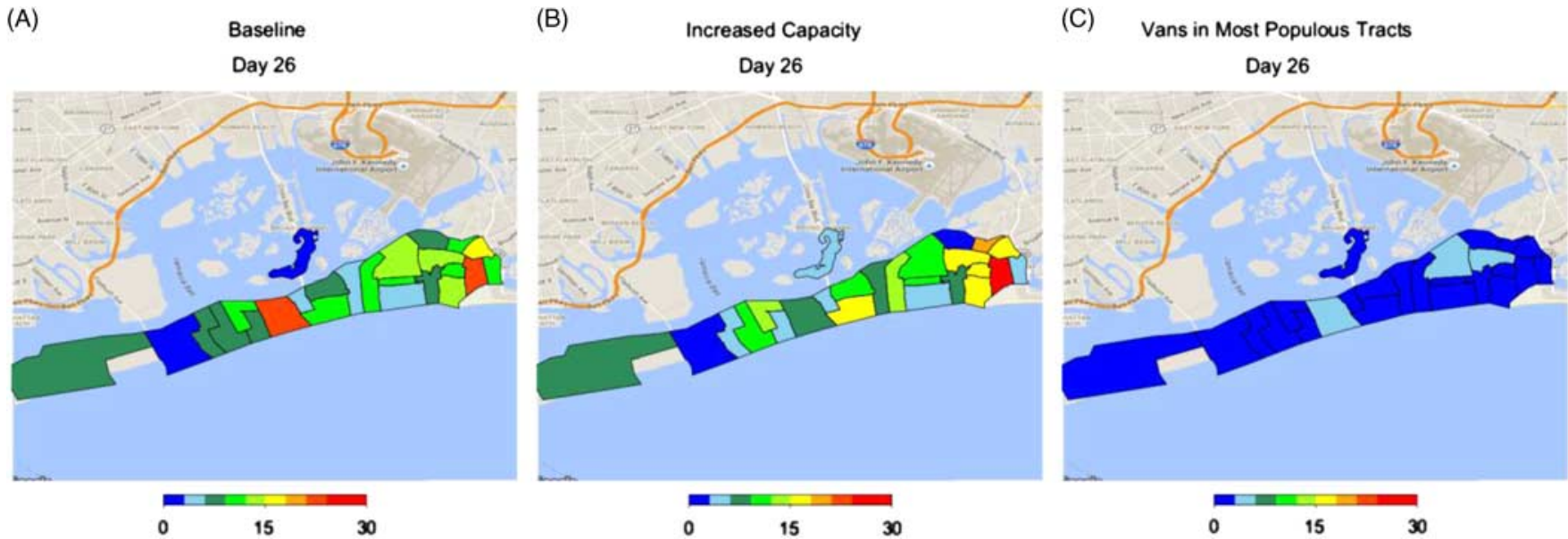

(A) Baseline. (B) A subset of providers increased their capacity by $50 \%$. (C) Mobile health centers were placed in the 6 most populous tracts. 


\section{FIGURE 5}

\section{Sensitivity of Primary Care Access Deficit in HAZEL to} Agent and Provider Behavior.

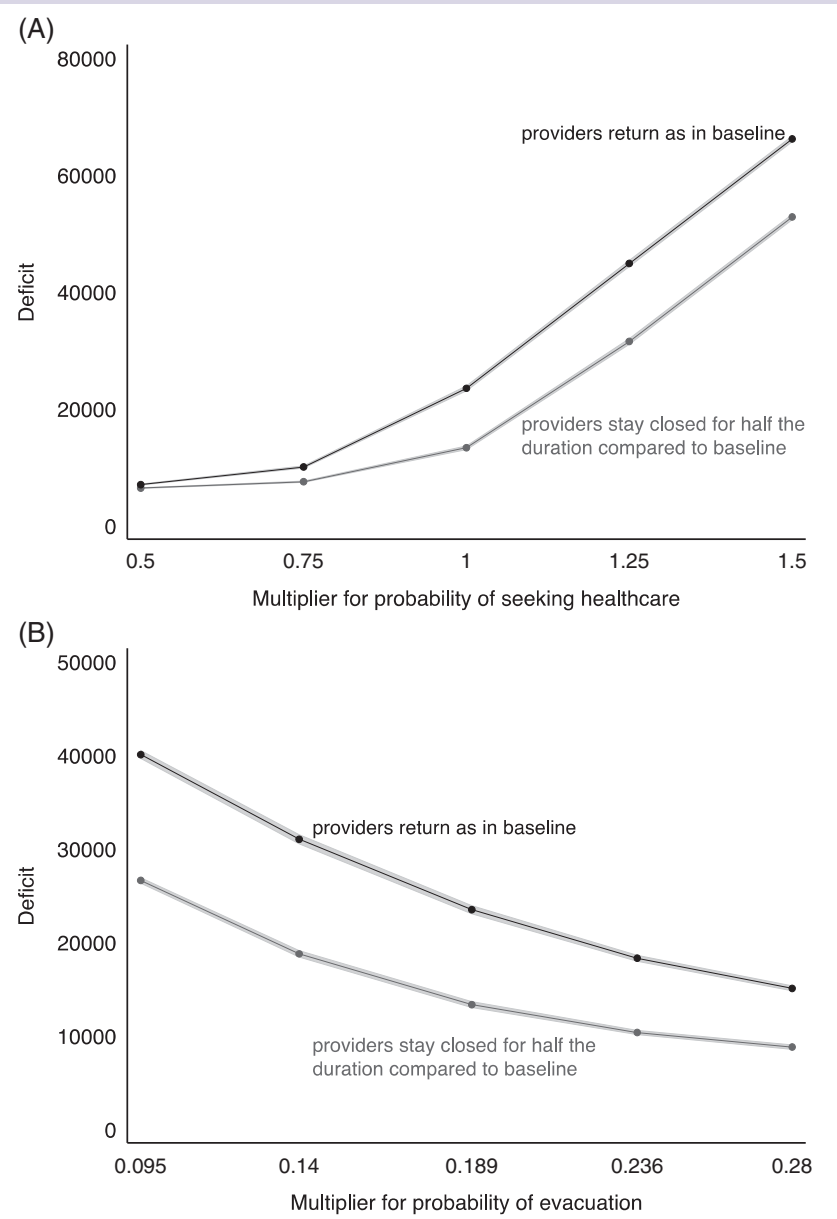

(C)

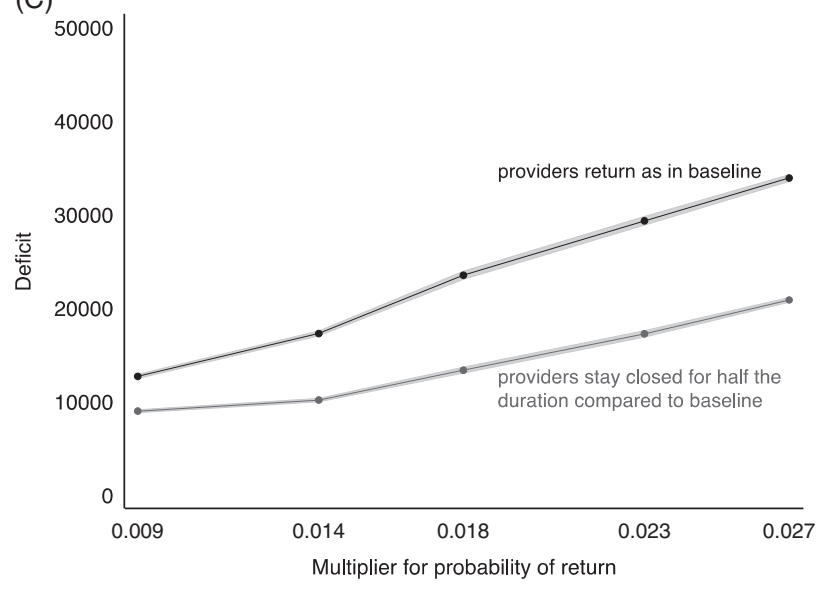

Parameters varied were (A) agent probability of seeking health care, (B) agent daily probability of evacuation, and (C) agent daily probability of returning after Hurricane Sandy. In all cases, the black curve signifies the total number of people who were unable to get health care at a provider who accepted their insurance if providers were closed as in the baseline, and the blue curve signifies deficit if providers were closed for half the length of time as they were in the baseline.

\section{DISCUSSION}

HAZEL is a novel simulation tool to assist in decision-making in the aftermath of a disaster, which may result in a public health emergency. Our results show that the tool is useful to simulate and examine dynamics in population and provider evacuation in the aftermath of a hurricane and its impact on primary care access. In scenarios designed to address the alternative intervention options decision-makers may be faced with, we were able to quantify the primary care access deficit. MHCs, which generally accept all insurance types and uninsured patients, were particularly effective at reducing the access deficit. After Hurricane Sandy, all but one MHC were active only for approximately 30 days ( $\mathrm{R}$ Sood, personal communication, 2015). We recognize that numerous factors play a role in length of deployment of MHCs, including the interest and resources of the MHC parent organization and the interest of public health officials to not provide disincentives that keep patients from visiting their regular health care provider if that provider's operations have resumed. Yet our model shows that given the changing dynamics of people returning to their homes in the Rockaways after Sandy and the number of days PCPs reported being closed, MHCs may need to be active for a longer duration to have a sustained impact on reducing an access deficit.

Our model shows that MHCs placed in the locations used by the New York State and New York City decision-makers in the aftermath of Hurricane Sandy were as effective at reducing the deficit as were MHCs placed in the most populous tracts. In the aftermath of Sandy, there was significant communication between residents of the Rockaways and community-based organizations on the location of MHCs. These locations were effectively communicated to government agencies. Our results suggest, however, that placing MHCs in the most populous tracts may be an effective strategy in the Rockaways in the absence of such a process or institutional memory, which enables public health and emergency management officials to formalize a strategy for coordination with MHC organizations to suggest deployment a strategy after a disaster.

Our model results are most sensitive to agents' daily probability of accessing health care. When agents accessed care with a daily probability above our baseline value (which was based on the literature), the access deficit rose steeply (Figure 4A). On the basis of this result, we suggest that additional clarity on the actual primary care utilization behavior of the specific population under study may increase the accuracy of model outputs.

HAZEL was created for the Rockaways, but its use can extend beyond this one region of New York City. Any geographic area in the United States, with inputs of health care provider locations, panel size, and distribution of insurance type and chronic condition prevalence, can parameterize HAZEL for their use. Owing to the small size of the resident population 
in the Rockaways, the estimated evacuation and return rates had wide margins of error based on the New York City DOHMH 2013 CHS. Sensitivity analyses, however, allowed us to examine the sensitivity of model results to these agent behaviors. A limitation of our model is that agents were assigned to providers on the basis of a generic gravity model owing to lack of data in the literature. We constrained agents to providers who accepted their insurance and whose specialty matched agent age. We believe these are reasonable assumptions because there is little information on how people choose their providers and the distance they travel in order to access a PCP under normal or emergency conditions. Finally, our assignment of Medicaid to households took into account household income but not poverty (ie, income given household size). Our method for Medicaid assignment did, however, ensure that insurance type was related to household income, and hence, spatially patterned in the Rockaways.

\section{CONCLUSIONS}

We have presented an agent-based modeling tool to examine primary care access based on a population distributed realistically in time and space. To our knowledge, this is the first agent-based model that examines access to health care. It demonstrates a novel tool available to decision-makers in the immediate aftermath of a disaster. Built by use of an opensource code base and publicly available population inputs, the tool can be extended beyond New York City's Rockaway peninsula given certain inputs related to PCPs. We expect that simulation models like HAZEL will be an important aspect of decision-making in rapidly changing situations, particularly in the aftermath of natural or man-made disasters.

\section{About the Authors}

Department of Health Policy and Management (Dr Guclu and Profs Hershey, Potter, van Nostrand), Department of Behavioral and Community Health Sciences (Dr Kumar), and Public Health Dynamics Laboratory (Mr Galloway, Dr Krauland), Graduate School of Public Health, University of Pittsburgh, Pittsburgh, Pennsylvania;Department of Biostatistics and Medical Informatics, School of Medicine, Istanbul Medeniyet University, Istanbul, Turkey (Dr Guclu); and the Bureau of Primary Care Access and Planning, New York City Department of Health and Mental Hygiene, New York, New York (Mr Sood, Ms Bocour). Drs Guclu and Kumar contributed equally to this work.

Correspondence and reprint requests to Hasan Guclu, PhD (Department of Health Policy and Management, guclu@pitt.edu) and Supriya Kumar, PhD, MPH (Department of Behavioral and Community Health Sciences, supriya@pitt.edu), Graduate School of Public Health, University of Pittsburgh, 130 DeSoto St, Pittsburgh, PA 15261.

\section{Acknowledgments}

We thank Tanya Shah and Maryellen Tria, both of the New York City Department of Health and Mental Hygiene at the time of our study, who were co-investigators on Project Number 1 HITEP130004-01-00. We also thank Kaitlin Piper of the University of Pittsburgh for her literature search on primary care utilization parameters.

\section{Funding}

Funded through the University of Pittsburgh Center for Public Health Practice by The Assistant Secretary for Preparedness and Response Project Number 1 HITEP130004-01-00.

\section{Disclaimer}

The opinions, results, findings, and/or interpretations of data contained herein are solely the responsibility of the authors and do not represent the opinions, interpretation, or policy of the US Centers for Disease Control and Prevention, the New York City Department of Health and Mental Hygiene, or the City of New York.

\section{Supplementary material}

For supplementary material/s referred to in this article, please visit http://dx.doi.org/10.1017/dmp.2016.44

Published online: April 14, 2016.

\section{REFERENCES}

1. Hurricane/Post-Tropical Cyclone Sandy, October 22-29, 2012. United States National Oceanic and Atmospheric Administration's National Weather Service. http://www.nws.noaa.gov/os/assessments/pdfs/Sandy13. pdf. Published May 2013. Accessed March 17, 2016.

2. Jacobson J. A long, for some too slow, health care recovery after Sandy. Am J Nurs. 2013;113(2):19-21. http://dx.doi.org/10.1097/01.NAJ. 0000426679.13364.d6.

3. Redlener I, Reilly MJ. Lessons from Sandy-preparing health systems for future disasters. N Engl J Med. 2012;367(24):2269-2271. http://dx.doi. org/10.1056/NEJMp1213486.

4. Teperman S. Hurricane Sandy and the greater New York health care system. J Trauma Acute Care Surg. 2013;74(6):1401-1410. http://dx. doi.org/10.1097/TA.0b013e318296fa9f.

5. Sebek K, Jacobson L, Wang J, et al. Assessing capacity and disease burden in a virtual network of New York City primary care providers following Hurricane Sandy. J Urban Health. 2014;91(4):615-622. http:// dx.doi.org/10.1007/s11524-014-9874-7.

6. Subaiya S, Moussavi C, Velasquez A, et al. A rapid needs assessment of the Rockaway Peninsula in New York City after Hurricane Sandy and the relationship of socioeconomic status to recovery. Am J Public Health. 2014;104(4):632-638. http://dx.doi.org/10.2105/AJPH.2013.301668.

7. VanDevanter N, Kovner CT, Raveis VH, et al. Challenges of nurses' deployment to other New York City hospitals in the aftermath of Hurricane Sandy. J Urban Health. 2014;91(4):603-614. http://dx.doi.org/ 10.1007/s11524-014-9889-0.

8. Lee DC, Smith SW, Carr BG, et al. Redistribution of emergency department patients after disaster-related closures of a public versus private hospital in New York City. Disaster Med Public Health Prep. 2015;9(3):256-264. http://dx.doi.org/10.1017/dmp.2015.11.

9. Adalja AA, Watson M, Bouri N, et al. Absorbing citywide patient surge during Hurricane Sandy: a case study in accommodating multiple hospital evacuations. Ann Emerg Med. 2014;64(1):66-73. 10.1016/j. annemergmed.2013.12.010.

10. Powell T, Hanfling D, Gostin LO. Emergency preparedness and public health: the lessons of Hurricane Sandy. JAMA. 2012;308 (24):2569-2570. http://dx.doi.org/10.1001/jama.2012.108940.

11. Murakami N, Siktel HB, Lucido D, et al. Disaster preparedness and awareness of patients on hemodialysis after Hurricane Sandy. Clin J Am Soc Nephrol. 2015;10(8):1389-1396. http://dx.doi.org/10.2215/CJN.10181014.

12. Lin CJ, Pierce LC, Roblin PM, et al. Impact of Hurricane Sandy on hospital emergency and dialysis services: a retrospective survey. Prehosp Disaster Med. 2014;29(4):374-379. http://dx.doi.org/10.1017/S1049023X14000715.

13. David-West G, Musa F, Frey MK, et al. Cross-sectional study of the impact of a natural disaster on the delivery of gynecologic oncology care. Disaster Med Public Health Prep. 2015;9(6):605-608. http://dx.doi.org/ 10.1017/dmp.2015.83. 
14. Grimm V, Railsback SF. Individual-Based Modeling and Ecology. Princeton, NJ: Princeton University Press; 2005. http://dx.doi.org/ 10.1515/9781400850624.

15. Krol DM, Redlener M, Shapiro A, et al. A mobile medical care approach targeting underserved populations in post-Hurricane Katrina Mississippi. J Health Care Poor Underserved. 2007;18(2):331-340. http://dx.doi.org/ 10.1353/hpu.2007.0038.

16. Lien C, Raimo J, Abramowitz J, et al. Community healthcare delivery postHurricane Sandy: lessons from a mobile health unit. J Community Health. 2014;39(3):599-605. http://dx.doi.org/10.1007/s10900-013-9805-7.

17. Marshall BD, Galea S. Formalizing the role of agent-based modeling in causal inference and epidemiology. Am J Epidemiol. 2015;181(2):92-99. http://dx.doi.org/10.1093/aje/kwu274.

18. Grefenstette JJ, Brown ST, Rosenfeld R, et al. FRED (a Framework for Reconstructing Epidemic Dynamics): an open-source software system for modeling infectious diseases and control strategies using census-based populations. BMC Public Health. 2013;13(1):940. http://dx.doi.org/ 10.1186/1471-2458-13-940.

19. Lee BY, Brown ST, Cooley P, et al. Simulating school closure strategies to mitigate an influenza epidemic. J Public Health Manag Pract. 2010; 16(3):252-261. http://dx.doi.org/10.1097/PHH.0b013e3181ce594e.

20. Brown ST, Tai JH, Bailey RR, et al. Would school closure for the 2009 H1N1 influenza epidemic have been worth the cost? A computational simulation of Pennsylvania. BMC Public Health. 2011;11(1):353. http:// dx.doi.org/10.1186/1471-2458-11-353.

21. Kumar S, Grefenstette JJ, Galloway D, et al. Policies to reduce influenza in the workplace: impact assessments using an agent-based model. Am J Public Health. 2013;103(8):1406-1411. http://dx.doi.org/10.2105/ AJPH.2013.301269.

22. Cooley P, Brown S, Cajka J, et al. The role of subway travel in an influenza epidemic: a New York City simulation. J Urban Health. 2011; 88(5):982-995. http://dx.doi.org/10.1007/s11524-011-9603-4.
23. Kumar S, Piper K, Galloway DD, et al. Is population structure sufficient to generate area-level inequalities in influenza rates? An examination using agent-based models. BMC Public Health. 2015;15(1):947. http://dx. doi.org/10.1186/s12889-015-2284-2.

24. Rodrigue J-P, Comtois C, Slack B. The Geography of Transport Systems, 3rd ed. Abingdon, Oxon: Routledge; 2013.

25. Community Health Survey. City of New York website. http://www.nyc. gov/html/doh/html/data/survey.shtml. Accessed March 17, 2016.

26. Dabelea D, Mayer-Davis EJ, Saydah S, et al. Prevalence of type 1 and type 2 diabetes among children and adolescents from 2001 to 2009. JAMA. 2014;311(17):1778-1786. http://dx.doi.org/10.1001/ jama.2014.3201.

27. Bloom B, Jones JI, Freeman G. Summary Health Statistics for U.S. Children: National Health Interview Survey, 2012. National Center for Health Statistics. Vital Health Stat. 2013;10(258). http:// www.cdc.gov/nchs/data/series/sr_10/sr10_258.pdf. Accessed March 17, 2016.

28. Petterson SM, Liaw WR, Phillips RL Jr, et al. Projecting US primary care physician workforce needs: 2010-2025. Ann Fam Med. 2012; 10(6):503-509. http://dx.doi.org/10.1370/afm.1431.

29. Lynch J, Honigfeld L. Insuring Our Kid's Future: The Importance of Health Insurance to Utilization of Pediatric Health Services. http:// citeseerx.ist.psu.edu/viewdoc/download?doi=10.1.1.542.2484\&rep=rep1\& type=pdf. Published October 2008. Accessed March 17, 2016.

30. Ostbye T, Yarnall KS, Krause KM, et al. Is there time for management of patients with chronic diseases in primary care? Ann Fam Med. 2005; 3(3):209-214. http://dx.doi.org/10.1370/afm.310.

31. Sood RK, Bocour A, S TB. Impact on primary care access post-disaster. Paper presented at: NACCHO Preparedness Summit; 2015; Atlanta, GA.

32. NYC.gov. Mobile Medical Van Locations. https:/web.archive.org/ web/20121112144745/http://www.nyc.gov/html/misc/html/2012/medical_ vans.html. Published November 12, 2012. Accessed March 17, 2016. 